\title{
Development Study of Turbulent $\kappa-\varepsilon$ Model for Recirculation Flow III: Two Dimension Recirculation Flow in a Reservoir
}

\author{
M. Syahril B. Kusuma, Rani A. Rahayu, Anom \& M. Cahyono \\ Faculty of Civil and Environmental Engineering
}

\begin{abstract}
An assessment of recirculation flow in Jatiluhur reservoir is conducted based on two dimensions turbulent $\kappa-\varepsilon$ model. The numerical model was developed using finite difference method where hydrodynamic equation was solved by the combination of Mc Cormack and splitting methods. The $\kappa-\varepsilon$ equation is solved using quickest scheme in convection term, central scheme in diffusion term and Euler scheme in reaction term. The simulations were done for maximum incoming flow during the rainy season and the dry season. Model results are compared to field measurement from which it is found that rainy season scenario has shown better agreement. Maximum incoming flow released in the rainy season could generate a boundary layer greater average velocity and more recirculation flow than that in the dry season. Further development is required to get more accurate results for the case with less average velocity.
\end{abstract}

Keywords: reservoir; two dimension recirculation flow; turbulent kappa-epsilon model.

\section{Introduction}

Reservoir is the most important resources of fresh water in Indonesia where water quality is the main issue of its feasibility.Many previous study have shown that DO (Dissolved Oxygen) is one of the important indicator of reservoir water quality. Water mass which has a good aeration will have a good level of DO. Water aeration process in reservoir depend on its mixing process. Based on the level of mixing process, H.B Fischer, et al. [1] distinguis reservoir water mass into three layer: epilimnion, hypolimnion and thermocline. Epilimnion layer is surface mixed layer where mixing process is generated by wind and convective flow. Thermocline is a sharp temperature transition layer separating the hypolimnion in the deeper mass waters from epilimnion layer. Hypolimnion, which is protected by thermocline layer from disturbance generated by flow dynamic in eplimnion, is anaerobic layer where vertical mixing process depend on density gradient. Wind breeze directly generate water aeration process through its radiation stress on surface water in eplimnion layer. Meanwhile flow dynamic, especially its recirculation flow, generate mixing process between water mass with higher DO with water mass with less DO.

Received May $16^{\text {th }}, 2008$, Revised August $29^{\text {th }}, 2008$, Accepted for publication May $27^{\text {th }}, 2009$. 
This mixing process could occure between epilimnion and hypolimnion layer or between aerated water mass with unaerated watermass in epilimnion layer. The dynamic of reservoir flow depend on the regulation of inflow and outflow of that reservoir. That is why the development of the model which is capable for assessing the dynamic of reservoir flow due to its operation becoming one of the interesting subject on numerical model research in Indonesia.

The dynamic of reservoir flow is governed not only by the advection term but also by the mixing term. The significant forces governing the dynamic of reservoir flow could be effectively determined by using the mean residence time of the reservoir ([1]) which is defined as the volume of the reservoir divided by the mean inflow rate. Based on this criterion, Jatiluhur reservoir which have short time resident is categorized as small reservoir where the governing forces of water quality dynamic could be derived from the equilibrium of inflowoutflow forces.

Most of the reservoir flow is three dimension flow where its flow regime depends on not only to the flow velocity but also to the reservoir geometry. The generation of recirculation zones due to the complex geometry of channel flow is discussed by Driver and Seegmiller [2], Hunt [3] and Hussain [4]. The complexity of reservoir geometry is usually developed by a sudden change of reservoir geometry such as canal expansion, canal contraction, canal bed step etc. Therefore, a precise and efficient simulation requires a grid system expressing this line of flow. Mesh refinement study to express the geography is one of practical options for this problem. For practical engineering problem solving, a small reservoir flow is frequently assessed using two dimension flow equation for shallow water condition where vertical velocity distribution is approached with the depth average velocity methods. The main stream of a reservoir flow along its thalweg, which is dominated by advection term, could be well enough predicted by this approach. Its secondary stream, which is generated during the rainy season by the influence of the complexity of its geometry and usually dominated by unstable mixing layer, could only be well predicted by this approach when the turbulent term is added as it may have very weak advection velocity but significant turbulent intensity. Experimental studies have been conducted on the movement and deposition of fine sediment in different sections of the reservoir, and it has been determined that inflowing water plunges at the upper end of the reservoir due to the density difference [5], forming an underflow on the bed slope [6]. Although numerous laboratory experiments have been conducted, data obtained from field experiments are limited. The rapid progress in computer technology improve the accurate of numerical model ([7]-[9]) that could be used to fill the lack of field measurement for assessing the reservoir flow. 
Younus has developed a depth-averaged $\kappa-\varepsilon$ Turbulence Model for assessing free-surface flow. Based on field measurements at the Shichikashuku Reservoir, Japan and standard $\kappa-\varepsilon$ turbulent model, Umeda, Makoto, et al. [10] have studied the water quality and sediment distribution in stratified reservoir. By adopting an orthogonal curvilinear grid to discretize the reservoir geometry, the model achieves good accuracy and resolution of sediment concentration in the reservoir, but over estimates the downstream velocity due to inaccurate of its grid system to cope the complexity of the reservoir geometry. Farrell and Stefan [11] constructed a vertical two-dimensional (2D) flow simulation model based on a $\kappa-\varepsilon$ turbulence model in cylindrical coordinates and discussed the plunge depth of the density current. Younus, Muhammad [12] and Ni, H.Q., Shen [13] has successfully developed a two dimension $\kappa-\varepsilon$ turbulence model by applying a depth average velocity for free surface flow. Choi and Garcia [14] simulated the density underflow and examined the repeatability of vertical structures of velocity and concentration in comparison with experimental data. Chung and $\mathrm{Gu}$ [15] applied a 2D model to analysis of the Shasta Reservoir during periods of thermal stratification through the simulated diffusion of a chemical (not suspended sediment) carried by the penetrating density current, and the model was shown to successfully reproduce the plunge flow and interflow of the density current. Measuring the flow pattern for all possible inflow-outflow condition is the most accurate and cost effective way for determining the characteristic of reservoir flow [16]. While using an appropriate numerical model could significantly reduce the cost for assessing reservoir flow characteristic with an acceptable level of accuracy.This paper attempts to discuss the results the application of $\kappa-\varepsilon$ turbulence model for assessing the recirculation flow in Jatiluhur Reservoir.

\section{Description of Jatiluhur Reservoir}

Jatiluhur Reservoir is located in the Citarum River Catchment Area where there are also located Cirata Reservoir and Saguling Reservoir. It has a geometry as it is shown in Figure 1. It has a surface area of about $\pm 83 \mathrm{~km}^{2}$, an average daily incoming flow of $175 \mathrm{~m}^{3} / \mathrm{s}$, a spillway width of $200 \mathrm{~m}$, a storage capacity of $3 \times 10^{9} \mathrm{~m}^{3}$ and a flood discharge capacity of $3,000 \mathrm{~m}^{3} / \mathrm{s}$. The mass curve of this reservoir is shown in figure 2 . The water quality of this reservoir is monitored in several measurement station once a year. Table 1 has shown the result of DO measurement in several measurement station. Based on the data measurement of 2005 monitoring work, the mean temperature of water surface is $25^{\circ} \mathrm{C}$, the wind velocity over the reservoir surface is $2.22 \mathrm{~m} / \mathrm{s}$ and the mean concentration of DO is $6.05 \mathrm{mg} / \mathrm{l}$. As the most downstream of that three cascade reservoir, Jatiluhur Reservoir reserve runoff discharge from Citarum River in its upstream and the released discharge from Cirata reservoir. 


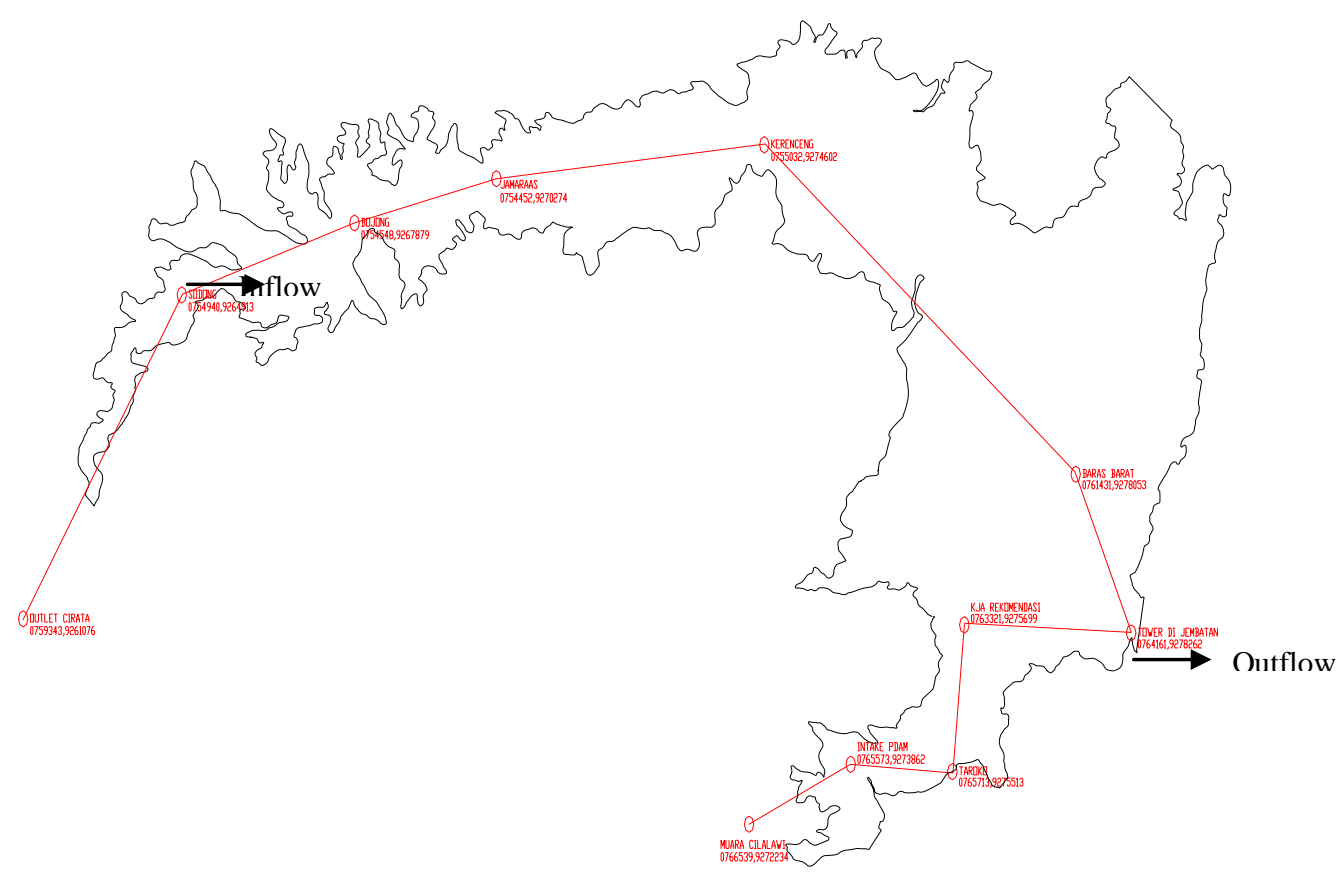

Figure 1 Geometry and Measurement Station of Jatiluhur Reservoir.

Table 1 DO Concentration based on field measurement on 20 February 2005.

\begin{tabular}{lcc}
\hline \multicolumn{1}{c}{ Station } & Distance $(\mathbf{K m})$ & DO Concentarion $(\mathbf{m g} / \mathbf{L})$ \\
\hline Parungkalong & & 4.00 \\
Sodong & 5.10 & 2.5 \\
Bojong & & 2.1 \\
Jamaras & 33.8 & 8.4 \\
Kerenceng & 54.1 & 5.2 \\
Keramba & 59.48 & 7.3 \\
Cilalawi & & 6.2 \\
PDAM & 50.58 & 7.3 \\
Taroko & & 7.4 \\
Baras Barat & 71.39 & 7.6 \\
Dam & & 8.5 \\
\hline
\end{tabular}

In the last two decade, the quality of released water from Cirata reservoir is significantly decreased. In the same time the quality of reserved water in Jatiluhur Reservoir is also decreased due to the accumulated waste from fishery 
activity in its reservoir. Both conditions cause the decreasing quality of water supply from Jatiluhur Reservoir to Jakarta City. As it is believed that the recirculation flow of the reservoir has significant role to the dynamic of water quality distribution in Jatiluhur Reservoir, the development of tools for assessing the recirculation flow of Jatiluhur Reservoir becomes the most interesting research subject.

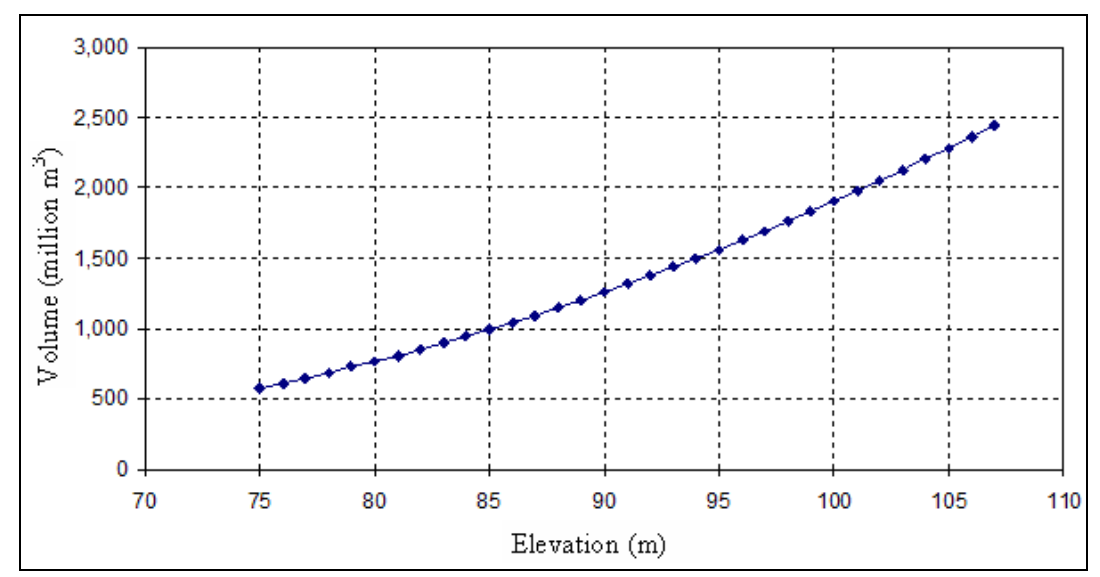

Figure 2 Reservoir mass curve.

Regulating the reservoir flow based on the best scenario resulted from such kind of tool is one of the effort that could mitigate the degradation of reservoir water quality. This effort could only be done when the reservoir flow characteristic of each scenario is already known.

\section{$3 \quad$ Model Description}

\subsection{Governing Equation and Numerical Solution}

The model was developed using finite difference method where hydrodynamic equation was solved by the combination of Mc Cormack and splitting methods. The detail description of the model could be seen in M. Syahril B.K et al [1720] where governing equation are developed based on the following basic assumptions:

a) Two dimension steady and incompressible flow

b) Cariolis force is negliable

c) Depth averaged velocity is applicable.

The $\kappa-\varepsilon$ equation is solved using quickest scheme in convection term, central scheme in diffusion term and Euler scheme in reaction term. Water quality 
equation is solved using quickest scheme. This developed model had been satisfactorily applied to assess flow pattern in several cases of open channel turbulent flow such as bending channel, expansion-contraction channel, non prismatic channel and fish pond/small reservoir (see M. Syahril B.K et al, [1720]). The governing equation of the model in depth average velocity form is as follow:

\section{Continuity Equation}

$$
\frac{\partial H}{\partial t}+\frac{\partial}{\partial x}(U H)+\frac{\partial}{\partial y}(V H)=0
$$

\section{Momentum equation for $x$ direction}

$$
\begin{aligned}
& \frac{\partial}{\partial t} H U+\frac{\partial}{\partial x} U^{2} H+\frac{\partial}{\partial y} U V H= \\
& \frac{\partial}{\partial x}\left[2 \hat{v}_{t}\left(\frac{\partial H U}{\partial x}-\frac{2}{3} H \hat{k}\right)\right]+\frac{\partial}{\partial y}\left[\hat{v}_{t}\left(\frac{\partial H U}{\partial y}+\frac{\partial H V}{\partial x}\right)\right]+\left[g H S_{o x}-\frac{g U \sqrt{U^{2}+V^{2}}}{C^{2}}+\frac{\rho_{a} C^{*} W_{x} W}{\rho}\right]
\end{aligned}
$$

\section{Momentum equation for y direction}

$$
\begin{aligned}
& \frac{\partial}{\partial t} H V+\frac{\partial}{\partial x} U V H+\frac{\partial}{\partial y} V^{2} H= \\
& \frac{\partial}{\partial x}\left[\hat{v}_{t}\left(\frac{\partial H U}{\partial y}+\frac{\partial H V}{\partial x}\right)\right]+\frac{\partial}{\partial x}\left[2 \hat{v}_{t}\left(\frac{\partial H V}{\partial y}-\frac{2}{3} H \hat{k}\right)\right]+\left[g H S_{o y}-\frac{g V \sqrt{U^{2}+V^{2}}}{C^{2}}+\frac{\rho_{a} C^{*} W_{y} W}{\rho}\right]
\end{aligned}
$$

\section{к equation (Chapman \& Kuo)}

$$
\frac{\partial(h \hat{k})}{\partial t}+\frac{\partial(h U \hat{k})}{\partial x}+\frac{\partial(h V \hat{k})}{\partial y}=\frac{\partial}{\partial x}\left[\frac{\hat{v}_{t}}{\sigma_{k}} \frac{\partial(h \hat{k})}{\partial x}\right]+\frac{\partial}{\partial y}\left[\frac{\hat{v}_{t}}{\sigma_{k}} \frac{\partial(h \hat{k})}{\partial y}\right]+p_{h}+p_{k}-\hat{\varepsilon} h
$$

E equation (Chapman \& Kuo)

$$
\frac{\partial(h \hat{\varepsilon})}{\partial t}+\frac{\partial(h U \hat{\varepsilon})}{\partial x}+\frac{\partial(h V \hat{\varepsilon})}{\partial y}=\frac{\partial}{\partial x}\left[\frac{\hat{v}_{t}}{\sigma_{k}} \frac{\partial(h \hat{\varepsilon})}{\partial x}\right]+\frac{\partial}{\partial y}\left[\frac{\hat{v}_{t}}{\sigma_{k}} \frac{\partial(h \hat{\varepsilon})}{\partial y}\right]+\frac{\hat{\varepsilon}}{\hat{\kappa}}\left(C_{1} p_{h}-C_{2} \hat{\varepsilon} h\right)+p_{\varepsilon}
$$




\section{Water Quality Equation}

$\frac{\partial(\Phi H)}{\partial t}+\frac{\partial(U \Phi H)}{\partial x}+\frac{\partial(V \Phi H)}{\partial y}=\frac{\partial}{\partial x}\left(D_{x} \frac{\partial(\Phi H)}{\partial x}\right)+\frac{\partial}{\partial y}\left(D_{y} \frac{\partial(\Phi H)}{\partial y}\right)$

where

$$
\begin{aligned}
& p_{h}=\frac{\hat{v}_{t}}{h}\left\{2\left[\frac{\partial(h U)}{\partial x}\right]^{2}+2\left[\frac{\partial(h V)}{\partial y}\right]^{2}+\left[\frac{\partial(h U)}{\partial y}\right]+\left[\frac{\partial(h V)}{\partial x}\right]\right\} \\
& p_{k}=\frac{g}{C^{2}} q^{3}, p_{\varepsilon}=\frac{C_{2} C_{\mu}^{1 / 2} g^{5 / 4} q^{4}}{h D^{1 / 2} C^{5 / 2}}, \mathrm{q}=\sqrt{\mathrm{U}^{2}+V^{2}}
\end{aligned}
$$

$C_{1}, C_{2}, \mathrm{C}_{\mu}, \sigma_{\mathrm{k}}, \sigma_{\varepsilon}$ and $\mathrm{D}$ are constant which are teken respectively as $1.44,1.92,0.09,1.0,1.3$ and 0.075 . The coefficient of $D_{x}$ and $D_{y}$ are taken as in our previous paper (see M. Syahril B.K., et al. [17], [20]). The description of Mac Cormack Scheme, splitting technique and quickest scheme are written in the following form.

a) Mc Cormack Scheme:

$$
\frac{\partial \mathrm{W}}{\partial \mathrm{t}}+\frac{\partial \mathrm{F}(\mathrm{W})}{\partial \mathrm{x}}+\mathrm{T}(\mathrm{W})=0
$$

Predictor

$$
\tilde{\mathrm{W}}_{\mathrm{i}}=\mathrm{W}_{\mathrm{i}}^{\mathrm{n}}-\frac{\Delta \mathrm{t}}{\Delta \mathrm{x}}\left[\mathrm{F}(\mathrm{w})_{\mathrm{i}+1}^{\mathrm{n}}-\mathrm{F}(\mathrm{w})_{\mathrm{i}}^{\mathrm{n}}\right]-\Delta \mathrm{tT}(\mathrm{w})^{\mathrm{n}}
$$

Corrector

$$
\begin{aligned}
& \mathrm{W}_{\mathrm{i}}=\mathrm{W}_{\mathrm{i}}^{\mathrm{n}}-\frac{\Delta \mathrm{t}}{\Delta \mathrm{x}}\left[\tilde{\mathrm{F}}(\mathrm{w})_{\mathrm{i}}-\tilde{\mathrm{F}}(\mathrm{w})_{\mathrm{i}-1}\right]-\Delta \mathrm{t} \tilde{\mathrm{T}}(\mathrm{w}) \\
& \mathrm{W}_{\mathrm{i}}^{\mathrm{n}+1}=\frac{\tilde{\mathrm{W}}_{\mathrm{i}}+\mathrm{W}_{\mathrm{i}}}{2}
\end{aligned}
$$


b) Quickest Scheme:

$$
\phi_{\mathrm{i}}^{\mathrm{n}+1}=\underbrace{\phi_{\mathrm{i}}^{\mathrm{n}}+\lambda\left[\widehat{\mathrm{F}}(\phi)_{\mathrm{i}+\frac{1}{2}}-\widehat{\mathrm{F}}(\phi)_{\mathrm{i}-\frac{1}{2}}\right]}_{\text {Convection }}+\underbrace{\left[\overline{\mathrm{D}} \hat{\mathrm{F}}(\phi)_{\mathrm{i}+\frac{1}{2}}-\overline{\mathrm{D}} \hat{\mathrm{F}}(\phi)_{\mathrm{i}-\frac{1}{2}}\right]}_{\text {Diffusion }}-\varphi \phi \Delta \mathrm{t}+\underbrace{\mathrm{q}_{\mathrm{s}} \mathrm{C}_{\mathrm{s}} \Delta \mathrm{t}}_{\text {Reaction }}
$$

c) Splitting Scheme:

$$
\mathrm{F}^{\mathrm{n}+2}=\left[\left(\mathrm{L}_{\mathrm{x}} \mathrm{L}_{\mathrm{y}} \mathrm{L}_{\mathrm{xx}} \mathrm{L}_{\mathrm{yy}} \mathrm{L}_{\mathrm{s}}\right) \bullet\left(\mathrm{L}_{\mathrm{s}} \mathrm{L}_{\mathrm{yy}} \mathrm{L}_{\mathrm{xx}} \mathrm{L}_{\mathrm{y}} \mathrm{L}_{\mathrm{x}}\right)\right] \mathrm{F}^{\mathrm{n}}
$$

where:

Lx $\quad=$ solution of first order differential equation in $x$ direction

Ly $\quad=$ solution of first order differential equation in y direction

Lxx $\quad=$ solution of second order differential equation in $x$ direction

Lyy $=$ solution of second order differential equation in y direction

Ls $\quad=$ solution of reaction equation

\subsection{Discretization}

The model domain is discretized by using $91 \mathrm{x} 63$ orthogonal grids of $\Delta \mathrm{x} \& \Delta \mathrm{y}$. The use of orthogonal grid in the grid system give a straight boundary line of the reservoir geometry. The grids system is arranged to fit the simplified reservoir geometry. The simplification is done to get a homogeneous square element along the complex reservoir shore line so that related numerical instability and error could be avoided (see Figure 3 and Table 2). Those grids are taken equal as long as $200 \mathrm{~m} / \mathrm{grid}$. The time interval $\Delta \mathrm{t}$ is taken as 0.5 second. The model is run during 120 hours.

Table 2 Total Grid over the model domain of Jatiluhur Reservoir.

\begin{tabular}{lcll}
\hline Parameters & Unit & Physical Condition & Numerical Model \\
\hline Surface Area & $\mathrm{M}^{2}$ & $8310^{6}$ & $83.0810^{6}$ \\
Grid in water surface & Grid & 2075 & 2077 \\
Grid in land surface & Grid & 3658 & 3656 \\
Grid inside reservoir & Grid & 5733 & 5733 \\
\hline
\end{tabular}




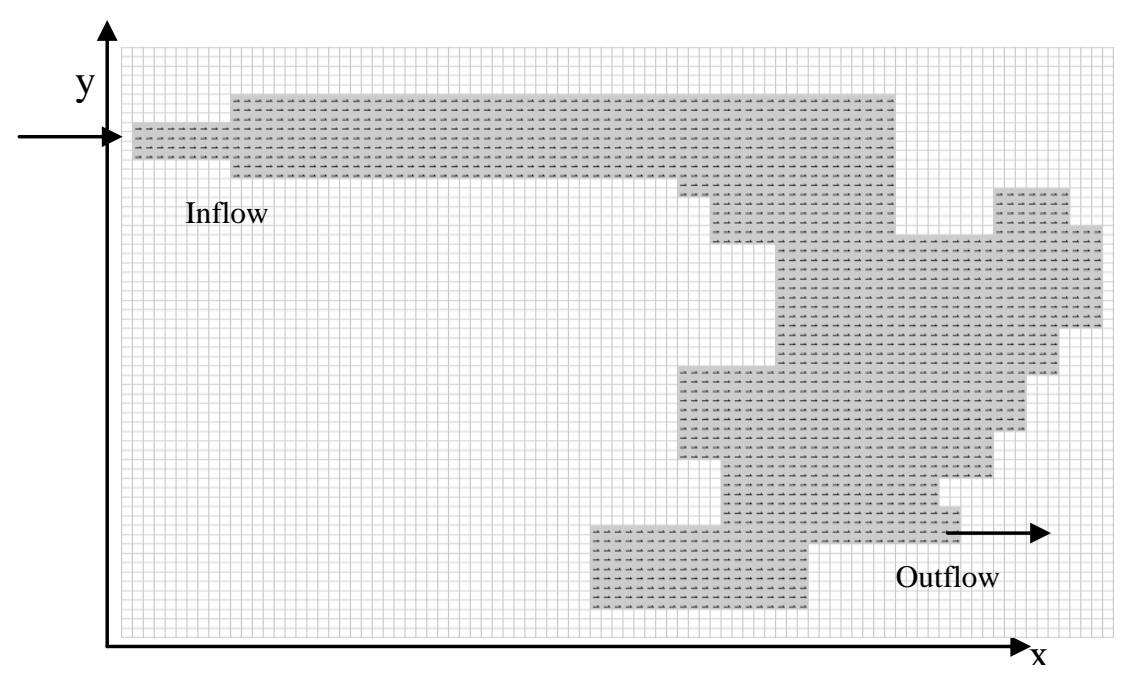

Figure 3 The grid system of the model.

The outflow is set up at the spillway of the reservoir which has $200 \mathrm{~m}$ width. The reservoir water quality is represented by the concentration of Dissolve Oxygen (DO). In this case, the model consider only water flow and wind blow velocity as the generator parameter of water aeration.

\subsection{Model Scenario}

The purpose of this model is to see the capacity of recirculation flow in increasing the DO distribution in the reservoir. In this case, this daily inflow is usually too small for generating recirculation flow in the reservoir so that it could not be encountered for increasing the DO concentration. That is why this paper discusses the possibility of using the maximum incoming flow to generate the recirculation flow which could increase the DO concentration in the reservoir. In this case the simulations were conducted for the following scenarios:

\section{a) Scenario 1 : Maximum incoming flow during the rainy season}

As the initial condition, it is assumed that the reservoir have reached its maximum water elevation at $+111.5 \mathrm{~m}$ above sea level, its DO concentration as it is shown in table 1 and its flow velocity at $0.02 \mathrm{~m} / \mathrm{sec}$. The boundary condition is set up by inflowing the maximum incoming flow with discharge as large as $3,000 \mathrm{~m}^{3} / \mathrm{sec}$ that should be released from Cirata during the rainy session and controlling the water level above the spillway by $\mathrm{Q}=\mathrm{CLH}_{\mathrm{e}}{ }^{3 / 2}\left(\mathrm{C}=\right.$ Discharge Coefficient, $\mathrm{L}=$ Width of the weir and $\mathrm{H}_{\mathrm{e}}$ is energy head above the weir). 


\section{b) Scenario 2 : Maximum incoming flow in the dry season}

As the initial condition, it is assumed that the reservoir have reached its minimum water elevation at $+107 \mathrm{~m}$ above sea level where its flow velocity at $0.02 \mathrm{~m} / \mathrm{sec}$ and its DO concentration is shown in Table 1 . The boundary condition is set up by inflowing the maximum incoming flow with discharge as large as $3,000 \mathrm{~m}^{3} / \mathrm{sec}$ that should be released from Cirata during the dry period and controlling the water level above the spillway by $\mathrm{Q}=\mathrm{CLH}_{\mathrm{e}}^{3 / 2}$.

Due the large surface ratio of reservoir to its river inlet, as it could be seen from Figure 2, the influence of the incoming flow to the reservoir water level increment is usually low so that the gradient of reservoir surface water is small. AS $k$ and $\varepsilon$ under quiescent conditions is theoretically zero, sufficiently small values of $k$ and $\varepsilon$ are set as initial values. Trial computations have shown that these initial conditions, could give a stable and near-equilibrium state within several hours of simulation, indicating that valid conditions are formed prior to intrusion of incoming flow under the boundary condition used in this study. The incoming flow velocity at the upstream end is given uniformly along the cross section of the intake. The velocity was obtained by dividing the flow rate at each time point by the area of the cross section.

\section{$4 \quad$ Results and Discussion}

Based on the model results it is shown that for scenario 1, the incoming flow of $3,000 \mathrm{~m}^{3} / \mathrm{s}$ could generate an outflow of $1,600 \mathrm{~m}^{3} / \mathrm{s}$ in the fist hour of running time and then increase until it reached $3,000 \mathrm{~m} 3 / \mathrm{s}$ in the $20^{\text {th }}$ hours of running time when the depth over the spillway crest reached $4.7 \mathrm{~m}$. No identification on the storage impact as the maximum reservoir level is set up as initial condition but the outflow discharge is approximately $7 \%$ higher than the incoming flow (see Figure 4a). Meanwhile for scenario 2, the incoming flow of $3,000 \mathrm{~m}^{3} / \mathrm{s}$ could generate an outflow of $1,000 \mathrm{~m}^{3} / \mathrm{s}$ in the $35^{\text {th }}$ hour of running time and then increase until it reached $2,500 \mathrm{~m} 3 / \mathrm{s}$ in the $120^{\text {th }}$ hours of running time. The gap between the incoming and the outcoming flow in scenario 2 (see Figure $4 \mathrm{~b}$ ) is generated by the storage impact as it is seen in Figure 2 where in the beginning the inflow discharge is used to store the water in the reservoir. Both scenario generate a subcritic flow (low froude number) as the flow depth of the reservoir is significantly increased compared to the river depth in its entrance. Most of DO concentration assessed by both scenario are smaller but have the same tendency compared to those of field observation where it is increasing toward to reservoir downstream. 


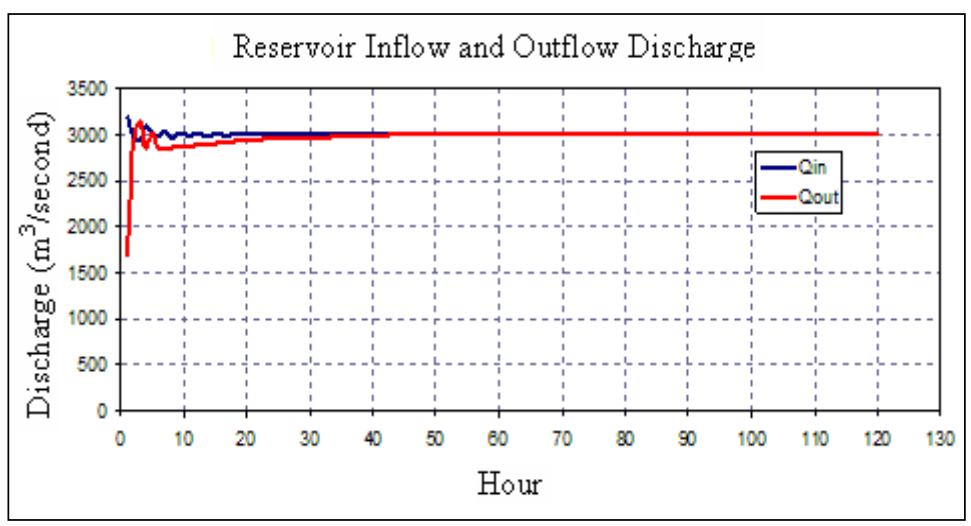

Figure 4a Storage Impact on Inflow and outflow discharge for scenario 1.

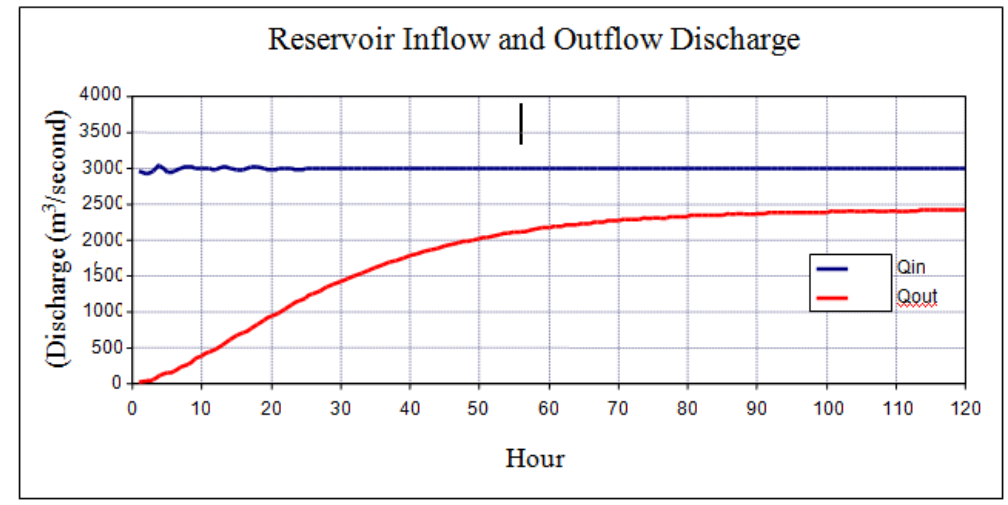

Figure 4b Storage Impact on Inflow and outflow discharge for scenario 2.

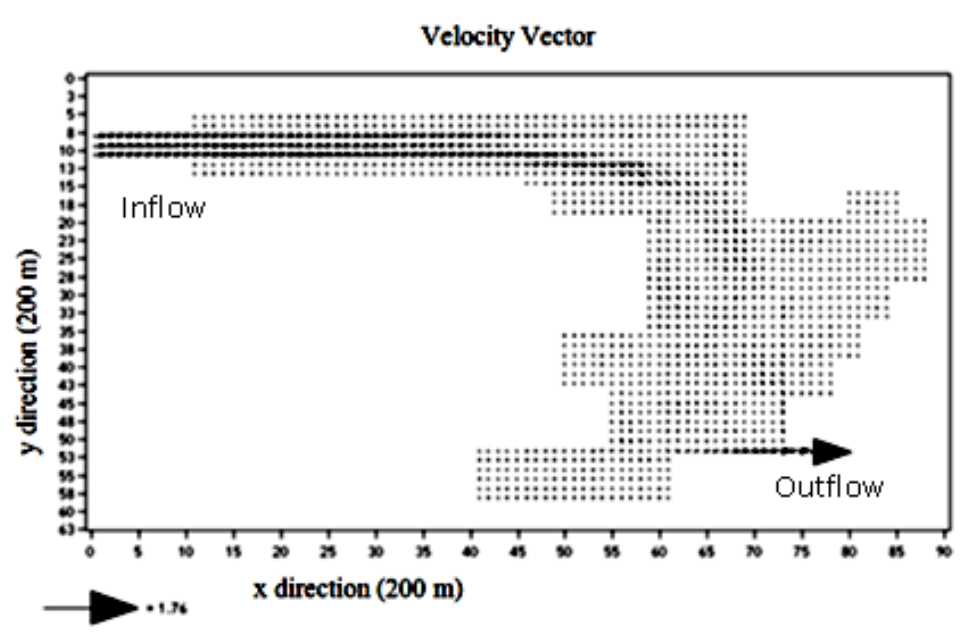

Figure 5a Velocity pattern in scenario 1. 


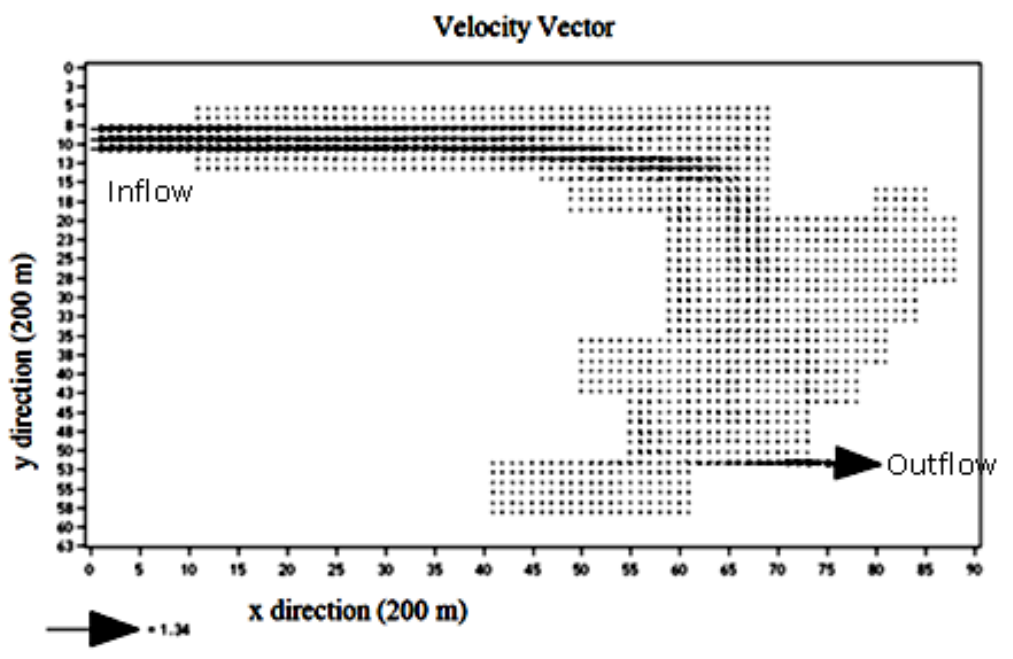

Figure 5b Velocity pattern in scenario 2.

Dissolved Oxygen Concentration ( $\mathrm{mg} / \mathrm{L}$ )

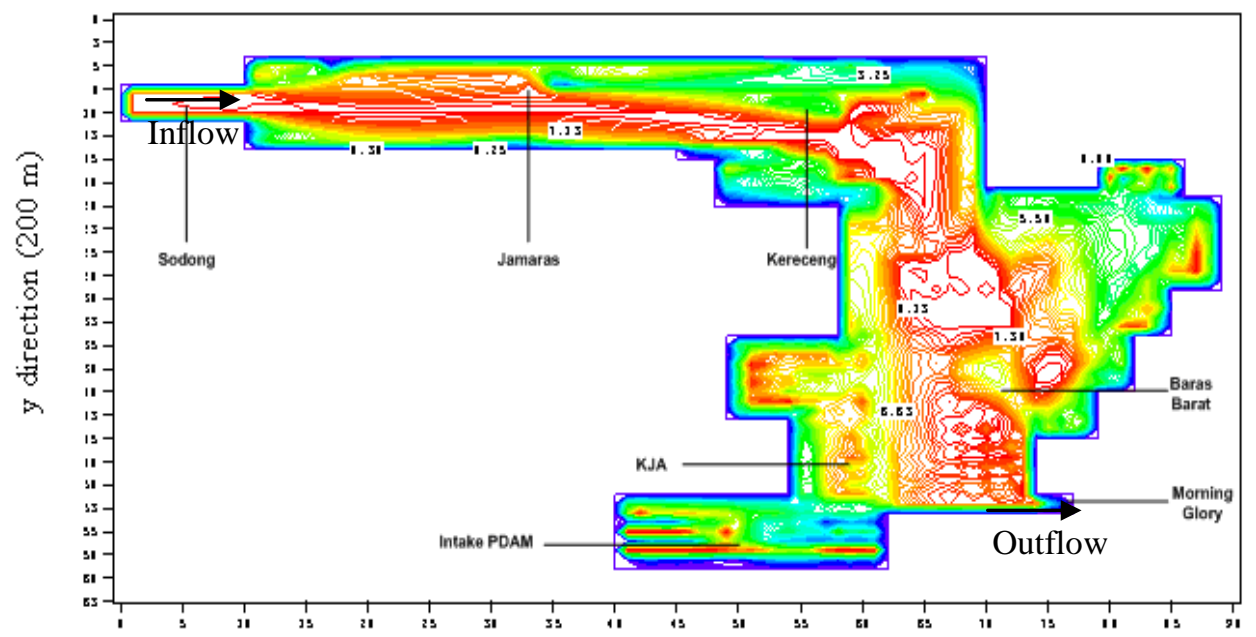

Figure 6a DO distribution after 120 hour for scenario 1 .

Compared to the scenario 2, the scenario 1 generate higher average velocity as there is higher outflow to generate reservoir flow. This cause scenario 1 has more capacity in generating recirculation flow and distributing higher DO concentration as it is significantly presented in Figure 5 and Figure 6. Based on the above results, it could then be concluded that the flood incoming flow could be used to increase the DO concentration more effective if the reservoir flow is regulated using the scenario 1 . 


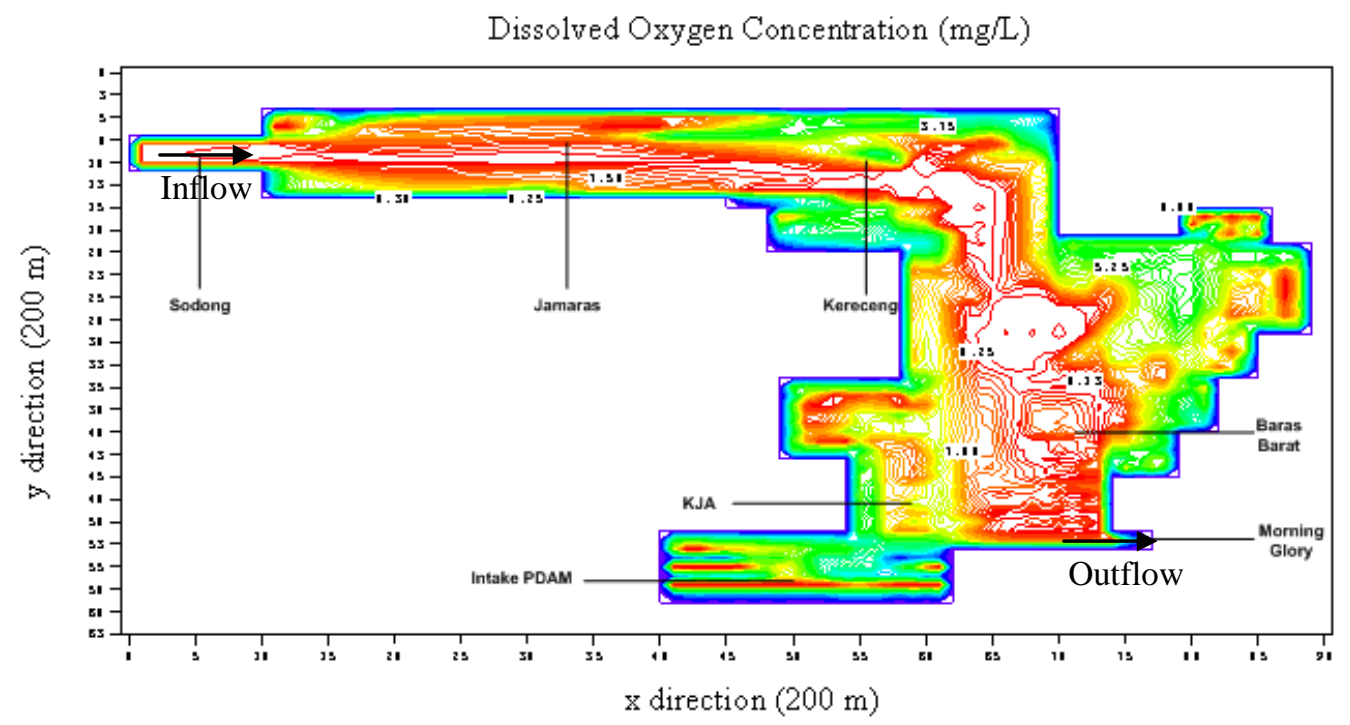

Figure 6b DO distribution after 120 hour for scenario 2.

The recirculation flow generated by both scenario as free shear layer, that started along reservoir thalweg and then horizontaly propagated accross the reservoir expantion with low velocity as it is found from visual field observation. However its instability, which is developed under the influence of depth variation and shape variation of reservoir beach, is less shown in the model results. Application of the depth averaged velocity, large grid and simplification of reservoir geometry have a significant contribution to the lack of this model in assessing this phenomenon. Therefore, further detail and accurate study based on three dimention model with more dense grid should be conducted to see more acuurate result in simulating this phenemoneon. In this case, field observation of vertical velocity distribution should be conducted to provide more accurate data for determening flow characteristic.

\section{Conclusion}

The simulation of recirculation flow in Jatiluhur reservoir generated by incoming flow released from Cirata Reservoir is conducted based on turbulent $\kappa-\varepsilon$ model. The model is conducted by implementing maximum incoming flow in two scenario: rainy season scenario and dry season scenario. Good 
comparison is found between the model results and field measurement. The maximum incoming flow released in the rainy season generated greater average velocity, more recirculation flow and better DO concentration than that in the dry season. Further study is required to perform more accurate results by developing three dimention model where more dense grid should be applied and more important reservoir paramater should be encountered such as its three dimention geometry, its vertical velocity distribution and its stratified vertical density. .

\section{Notations}

$$
\begin{aligned}
& \hat{v}_{t} \quad=C_{\mu} \frac{\hat{k}^{2}}{\hat{\varepsilon}}=\text { Depth averaged turbulent viscosity (Prandtl-Kolmogorov- } \\
& \text { Relationship, } \mathrm{m}^{2} / \mathrm{s} \text { ) } \\
& \text { g = gravitation }\left(\mathrm{m} / \mathrm{s}^{2}\right) \\
& \hat{\varepsilon} \quad=\text { epsilon or dissipation rate of turbulent energy per unit mass }\left(\mathrm{m}^{2} / \mathrm{s}^{3}\right) \\
& \hat{\kappa}=\text { kappa or turbulence kinetic energy per unit mass }\left(\mathrm{m}^{2} / \mathrm{s}^{2}\right) \\
& C_{\mu} \quad=\text { empirical constant }=0.09 \\
& C_{1} \quad=1.44, C_{2}=1.92, \mathrm{C}_{\mu}=0.09, \sigma_{\mathrm{k}}=1.0, \sigma_{\varepsilon}=1.3 \text { and } \mathrm{D}=0.075 \\
& \mathrm{U}=\text { Depth Average Velocity in } \mathrm{x} \text { Direction }(\mathrm{m} / \mathrm{s}) \\
& \mathrm{V}=\text { Depth Average Velocity in y Direction }(\mathrm{m} / \mathrm{s}) \\
& \mathrm{H} \quad \text { = Mean flow depth }(\mathrm{m}) \\
& \rho_{\mathrm{a}} \quad=\text { Air density }\left(\mathrm{kg} / \mathrm{m}^{3}\right) \\
& \mathrm{C}^{*} \quad=\text { Ekman Coeficient }=0.026 \\
& \mathrm{~W}_{\mathrm{x}} \quad=\text { Wind Velocity in } \mathrm{x} \text { direction }(\mathrm{m} / \mathrm{s}) \\
& \mathrm{W}_{\mathrm{y}} \quad=\text { Wind Velocity in } \mathrm{y} \text { direction }(\mathrm{m} / \mathrm{s}) \\
& \mathrm{W}=\sqrt{\mathrm{W}_{\mathrm{x}}+\mathrm{W}_{\mathrm{y}}} \\
& \Phi \quad=\text { Flux, water quality concentration } \\
& \mathrm{h} \quad=\text { flow depth }(\mathrm{m}) \\
& \rho \quad=\text { Fluid Density }\left(\mathrm{kg} / \mathrm{m}^{3}\right) \\
& \mu \quad=\text { Dynamic Viscosity }(\mathrm{Kg} / \mathrm{ms})
\end{aligned}
$$




$$
\begin{array}{ll}
v & =\text { Kinematic viscosity }\left(\mathrm{m}^{2} / \mathrm{s}\right) \\
\mathrm{D}_{\mathrm{x}} & =\text { Turbulent diffusion Coef in x direction }\left(\mathrm{m}^{2} / \mathrm{s}\right) \\
\mathrm{D}_{\mathrm{y}} & =\text { Turbulent diffusion Coef in y direction }\left(\mathrm{m}^{2} / \mathrm{s}\right) \\
\mathrm{C} & =\frac{R^{1 / 6}}{n}=\text { Chezy Coeficient }\left(\mathrm{m}^{1 / 2} / \mathrm{s}\right)
\end{array}
$$

\section{Acknowledgement}

The autors would like to thank the Asahi Glass Foundation and Jatiluhur Authority who have supported the research related to this paper.

\section{References}

[1] Fischer, H.B., List, E.J., Koh, R.C.Y., Brooks, N.H. \& Imberger, J., Mixing in Inland and Coastal Waters, Academic Press, New York, 1979.

[2] Driver, D.M \& Seegmiller, H. Lee, Features of Reattaching Turbulent Shear Layer in Divergent Channel, AIAA Journal, 23(21), 1985.

[3] Hunt, J.C.R, Coherent Structures-Comments on Mechanism, Seminar Proceeding of Von Karman Institute for Fluid Dynamics, Lecture Series03, 1989.

[4] Hussain, A.K.M.F. \& Clark, A.R., On The Coherent Structure Of The Axisymmetric Mixing Layer: A Flow Visualization Study, JFM 104, pp. 263-294, 1981.

[5] Akiyama, J. \& Stefan, H. G., Plunging Flow Into A Reservoir: Theory, J. Hydraulic. Eng., 110(4), 484-499, 1984.

[6] Alavian, V., Jirka, G.H., Denton, R.A., Johnson, M.C. \& Stefan, H.G., Density Currents Entering Lakes And Reservoirs, JHE., 118(11), 14641489, 1992.

[7] Abbott, M.B., Basco, D.R., Computational Fluid Dynamics an Introduction for Engineers, Longman Scientific \& Technical, England, 1989.

[8] Fletcher, C.A.J., Computational Techniques for Fluid Dynamics Volume I-II, Second Edition, Springer-Verlag, London, 1990.

[9] Anderson JR, J.D., Computational Fluid Dynamics, McGraw-Hill International Editions, New York, 1995.

[10] Umeda, Makoto, Yokoyama, Katsuhide \& Ishikawa, Tadaharu, M.ASCE, Observation and Simulation of Flood water Intrusion and Sedimentation in the Shichikashuku Reservoir, Journal of Hydraulic Engineering,132:9881, 2006.

[11] Farrel, G.J. \& Stefan, H.G., Mathematical Modeling Of Plunging Reservoir Flows, J. Hydraulic. Res., 26(5), 525-537, 1989. 
[12] Younus, Muhammad, Computation of Free-Surface Flow By Using Depth-Averaged $\kappa-\varepsilon$ Turbulence Model, Dissertation, Department of Civil and Environmental Engineering, Washington State University, 1993.

[13] Ni, H.Q., Shen, Y.M., Zhou, L.X., Duan, J.H., Numerical Simulation of Multiple Circulating Flows Using A Depth-Averaged $\kappa-\varepsilon$ Turbulence Model For The Entire Field, The Sixth Asian Congress of Fluid Mechanics, Singapore, 1995.

[14] Choi, S.U. \& Garcia, M.H., $k-\varepsilon$ Turbulence Modeling Of Density Currents Developing Two Dimensionally On A Slope, JHE., 128(1), 5563, 2002.

[15] Chung, S.W. \& Gu, R., Two-Dimensional Simulations Of Contaminant Currents In Stratified Reservoir, J. Hydraulic. Eng., 124(7), 704-711, 1998.

[16] Young-Oh Kim; Hyung-Il Eum; Eun-Goo Lee; and Ick Hwan Ko, Optimizing Operational Policies of a Korean Multy Reservoir System Using Sampling Stochastic Dynamic Programming with Ensemble Stream flow Prediction, Journal of Water Resources Planning And Management, 133:1-4, 2007.

[17] Kusuma, M. Syahril B., Rahayu, Rani A., Oktarianto, Eka, Kardana, Hadi \& Cahyono, M., Studi Pengembangan Model Turbulen $\kappa-\varepsilon$ untuk Sirkulasi Arus II: Aliran Turbulen Dua Dimensi pada Saluran Ekspansi, Proc. ITB Sains \& Tek., 39A(1\&2), pp. 70-96, 2007.

[18] Kusuma, M. Syahril B., Rahayu, R.A., Kardana, H. \& Cahyono, M., Numerical Simulation of Two Dimensional Turbulent Flow in Division Box of an Irrigation Channel Based on $\kappa-\varepsilon$ Model, Proceeding of International conference on Fluid and Thermal Energy Conversion, Jakarta, 2006.

[19] Kusuma, M. Syahril B., Rahayu, R.A., Kardana, H. \& Cahyono, M., Development Of Turbulent $\kappa-\varepsilon$ Model for Assessing Water Quality Distribution in Reservoir, Research Report, Asahi Research Grant, 2006.

[20] Kusuma, M. Syahril B., Cahyono, M. \& Oktarianto, Eka, Studi Pengembangan Model Turbulen $\kappa-\varepsilon$ untuk Sirkulasi Arus I: Aliran Dua Dimensi pada Sebuah Tampungan Air, Proc. ITB Sains \& Tek. 36A(2), pp. 179-204, 2004. 